\title{
Ozone induces tolerance against cardiomyocytes oxygen-glucose deprivation/reperfusion through inhibition of autophagy pathway
}

\author{
LINGSHAN XU ${ }^{1 *}$, LIANG ZHU²*, PING LIU ${ }^{2}$, ZHOUQUAN WU² and ZHIQING ZOU² \\ ${ }^{1}$ Department of Anesthesiology. Nanjing Medical University, Jiangning, Nanjing 211166; ${ }^{2}$ Department of Anesthesiology, \\ The Affiliated Changzhou Second People's Hospital of Nanjing Medical University, Changzhou, Jiangsu 213000, P.R. China
}

Received August 11, 2020; Accepted April 1,2021

DOI: $10.3892 / \mathrm{etm} .2021 .10301$

\begin{abstract}
Previous studies have reported that excess activation of autophagy in cardiomyocytes is associated with an increase in myocardial oxygen-glucose deprivation/reperfusion (OGD/R) injury. Ozone therapy affords significant cardio-protection against myocardial OGD/R injury. The present study was designed to determine whether ozone-induced tolerance to myocardial OGD/R injury was mediated by inhibiting autophagy. Subsequently, the rat cardio myoblast $\mathrm{H} 9 \mathrm{C} 2$ cell line was used in the present study. A model of $\mathrm{H} 9 \mathrm{C} 2$ cells under OGD/R was established. The cells were incubated with different concentrations of ozone (10-60 $\mu \mathrm{g} / \mathrm{ml})$ during reperfusion. Furthermore, to investigate the role of autophagy in OGD/R-induced injury, the autophagy inducer and inhibitor were applied. Cell viability was detected by Cell Counting kit- 8 assay. Cell apoptosis was evaluated by flow cytometry. Oxidative stress was examined by superoxide dismutase, lactate dehydrogenase and malondialdehyde levels. The expressions of apoptosis regulator B-cell lymphoma-2 (Bcl-2), Bcl-2 associated X protein (BAX), cleaved caspase-3, markers of autophagy microtuble-associated protein 1 light chain 3 (LC3), autophagy-related protein 5 (Atg5) and Beclin-1 were measured by western blot analysis. As a result, OGD/R notably decreased cell viability and induced apoptosis in $\mathrm{H} 9 \mathrm{C} 2$ cells, while ozone $(10-40 \mu \mathrm{g} / \mathrm{ml})$ reversed the noxious effects of OGD/R on H9C2 cells, and $20 \mu \mathrm{g} / \mathrm{ml}$ ozone was the most effective. Ozone inhibited the decrease in the ratio of $\mathrm{Bcl}-2 / \mathrm{BAX}$ and the expression of cleaved caspase-3, and inhibited the increase in the ratio of LC3-II/LC3-I and
\end{abstract}

Correspondence to: Dr Zhouquan Wu or Dr Zhiqing Zou, Department of Anesthesiology, The Affiliated Changzhou Second People's Hospital of Nanjing Medical University, 29 Xinglong Lane, Changzhou, Jiangsu 213000, P.R. China

E-mail:wuzhouquan2005@126.com

E-mail: 15544241@qq.com

${ }^{*}$ Contributed equally

Key words: ozone, myocardial, oxygen-glucose deprivation/ reperfusion, apoptosis, autophagy the expression of Atg5 and Beclin-1 elicited by OGD/R, as well as dose-dependently preventing OGD/R-induced oxidative stress. Furthermore, rapamycin markedly reversed the effects of ozone $(20 \mu \mathrm{g} / \mathrm{ml})$ on OGD/R-induced expression of autophagy marker proteins and 3-methyladenine further improved the effect of ozone. Taken together, the results of the present study provided a credible mechanism by which ozone treatment at low concentrations could protect the myocardium from OGD/R-induced injury by inhibiting autophagy.

\section{Introduction}

Myocardial ischemia injury is a complicated pathophysiological process. Although reperfusion remains the only efficient strategy for the survival of ischemic myocardial tissue by rescuing the cardiomyocytes and promoting myocardial remodeling, reperfusion itself often conversely induces the apoptosis of cardiomyocytes and exacerbates the damage to the myocardium, which is usually known as myocardial oxygen-glucose deprivation/reperfusion (OGD/R) injury $(1,2)$. Previous studies have testified that the cellular degradation, particularly autophagy, serves an important role in the process of myocardial ischemia/reperfusion injury $(3,4)$. Autophagy, the body's self-cleaning system, is reported to provide a necessary source of energy for cardiomyocytes during the early stage (5), which protects cardiomyocytes against ischemia/reperfusion injury (6). By contrast, autophagy could also aggravate the apoptotic and cytotoxic death of cardiomyocytes during the late stage of ischemia and reperfusion (7). Therefore, autophagy is of great interest among the mechanisms involved in OGD/R-induced injury of cardiomyocytes.

Ozone is a molecule consisting of three atoms of oxygen, the basic function of which is to absorb incoming UV radiation and protect humans from the damages of UV (8). Ozone, as a superoxide involved in the activation of a variety of antioxidant enzymes (9), is widely used in inhibiting inflammatory injury $(10,11)$ by downregulating the expression of inflammatory mediators [interleukin-6 (IL-6), interleukin-8 (IL-8) and tumor necrosis factor- $\alpha($ TNF- $\alpha)$ ]. Previous studies have further reported that ozone has significant therapeutic effects on chronic ischemic diseases (including limb and kidney damage) $(12,13)$ and myocardial ischemia/reperfusion injury through activating the antioxidant system by induction of transient oxidative stress and promoting the release of oxygen 
to tissues (9). Of note, it was reported that reactive oxygen species (ROS) could act as an early inducer of autophagy upon nutrient deprivation $(14)$. Chen et al $(15,16)$ reported that $\mathrm{O}_{2-}$ is the primary ROS involved in autophagy induced by deprivation of glucose, glutamine, pyruvate or serum $(15,16)$. However, the role of ozone and the molecular mechanism associated with its effect on OGD/R-induced myocardial injury has not yet been reported.

Autophagy is a catabolic process aimed at recycling cellular components and damaged organelles in response to diverse conditions of stress, including nutrient deprivation, viral infection and genotoxic stress (17). The results of a previous study suggested that oxidative stress acts as the converging point of these stimuli, and ROS and reactive nitrogen species are regarded as the main intracellular signal transducers of the autophagy pathway (18). The present study investigated the protective effects of ozone on OGD/R-induced cardiomyocytes injury using pharmacologic analysis, and whether ozone-induced tolerance to myocardial OGD/R injury was mediated by inhibiting autophagy.

\section{Materials and methods}

Ozone preparation. An ozone-generating device (Shenyang Medicines \& Health Products; HUMARES ${ }^{\circledR} \mathrm{GmbH}$ ) was used to generate the mixed gas. The operating procedure was as the follows: Adding $3 \mathrm{ml}$ of DMEM (Thermo Fisher Scientific, Inc.) into a centrifuge tube and collecting $3 \mathrm{ml}$ of ozone gas from an ozone-generating device into sterile syringe, then pumping the ozone into DMEM through a sterile plastic tube and mixing the gas and DMEM on the oscillator for $5 \mathrm{~min}$. Subsequently, the mixed culture medium was used to cultivate the cells during reperfusion.

Cell culture. The rat cardiomyocyte H9C2 cell line was obtained from BeNa Culture Collection (Beijing Beina Chunglian Institute of Biotechnology). Cells were grown in complete high-glucose DMEM, supplemented with $10 \%$ fetal bovine serum (Biological Industries) and antibiotics $(100 \mu \mathrm{g} / \mathrm{ml} \mathrm{strep-}$ tomycin and $100 \mathrm{U} / \mathrm{ml}$ penicillin; Thermo Fisher Scientific, Inc.). The cells were incubated in a humidified incubator at $37^{\circ} \mathrm{C}$ with $5 \% \mathrm{CO}_{2}$.

Establishment of an OGD/R injury model. The OGD/R injury model was established as previously described (19). In order to mimic oxygen-glucose deprivation, the cells were incubated in serum- and glucose-free DMEM (Thermo Fisher Scientific, Inc.) and placed in a hypoxia chamber $\left(95 \% \mathrm{~N}_{2}\right.$ and $5 \% \mathrm{CO}_{2}$ at $37^{\circ} \mathrm{C}$ ) for $6 \mathrm{~h}$. Next, the cells were returned to culture under normal conditions $\left(95 \%\right.$ humidified air and $5 \% \mathrm{CO}_{2}$ at $37^{\circ} \mathrm{C}$ ) with complete high-glucose DMEM for $4 \mathrm{~h}$ to mimic the reperfusion.

Cell treatment. The cells were divided into the following groups: Control group, in which cells were cultured in DMEM; Model group, in which cells underwent OGD/R injury; OGD/R+O3 group, in which cells were treated with different concentrations of ozone during reperfusion at $37^{\circ} \mathrm{C}$ for $4 \mathrm{~h}$; OGD/R+O3+Rapa group, in which cells were treated with 100 nmol Rapamycin (Sigma-Aldrich;
Merck $\mathrm{KGaA}$ ) at $37^{\circ} \mathrm{C}$ for $2 \mathrm{~h}$ prior to establishing the model; OGD/R+O3+3-MA group, in which cells were treated with $5 \mathrm{mmol} 3$-MA (Selleck Chemicals) at $37^{\circ} \mathrm{C}$ for $2 \mathrm{~h}$ prior to establishing the model.

Cell Counting kit-8 (CCK-8) assay. The cells were incubated in 96-well plates (5x103 cells/well) for $24 \mathrm{~h}$. Next, the cells were used to establish the OGD/R injury model and the cells were treated with different concentrations of ozone $(10,20$, 40 and $60 \mu \mathrm{g} / \mathrm{ml}$ ) when mimicking reperfusion. Following culture, CCK-8 solution (Dojindo Molecular Technologies, Inc.) was added and the plate was incubated in the dark for $2 \mathrm{~h}$, followed by measurement of the OD value at $450 \mathrm{~nm}$ using a microplate absorbance reader (BioTek China).

Cell apoptosis assay. Cell apoptosis levels was detected using a Annexin V-fluorescein isothiocyanate (FITC)/propidium iodide (PI) apoptosis detection kit (Vazyme Biotech Co., Ltd.). In brief, the cells were incubated at a density of $3.5 \times 10^{5}$ cells/well in 6 -well plates and were collected and stained with $5 \mu \mathrm{l}$ Annexin V-FITC and $5 \mu \mathrm{l}$ PI solution in the dark for $15 \mathrm{~min}$ at room temperature after oxygen-glucose deprivation/reperfusion. Subsequently, the stained cells were analyzed using a flow cytometer (FACScan ${ }^{\mathrm{TM}}$; BD Biosciences) and Modfit software 3.2 (Verity Software House, Inc.).

Detection of lactate dehydrogenase ( $L D H)$. LDH activity was examined using an LDH detection kit (cat. no. BC0680; Beijing Solarbio Science \& Technology Co., Ltd.), according to the manufacturer's protocol. The cells were lysed on ice using an ultrasonic cell breaker (Ningbo Scientz Biotechnology Co., Ltd.). Next, the cells were exposed to reagent I and reagent II and incubated in a $37^{\circ} \mathrm{C}$ water bath for $15 \mathrm{~min}$. Subsequently, reagent III was added and the cells were incubated in the water bath again for $15 \mathrm{~min}$. Finally, reagent IV was added to the mixture and incubated at room temperature for $3 \mathrm{~min}$. The OD value was measured at $560 \mathrm{~nm}$ using a light absorption microplate reader (BioTek China).

Detection of malondialdehyde (MDA) The MDA detection kit (cat. no. BC0020; Beijing Solarbio Science \& Technology Co., Ltd.) was used to detect the content of MDA, according to the manufacturer's protocol. The cells were lysed and then mixed with reagent I and reagent III. Subsequently, the mixture was heated in boiling water for $30 \mathrm{~min}$, and centrifuged at $10,000 \mathrm{x} \mathrm{g}$ at room temperature for $10 \mathrm{~min}$. The OD value was measured at 532, 450 and $600 \mathrm{~nm}$ using a light absorption microplate reader (BioTek China).

Detection of superoxide dismutase (SOD). SOD activity was detected using the SOD detection kit (cat. no. BC0170; Beijing Solarbio Science \& Technology Co., Ltd.), according to the manufacturer's protocol. The cells were lysed on ice and the lysate was mixed with reagent I to IV, and was then kept at room temperature for $30 \mathrm{~min}$. The OD value was measured at $560 \mathrm{~nm}$ using a light absorption microplate reader (BioTek China).

Western blot analysis. Radio Immunoprecipitation Assay (RIPA; Beyotime Institute of Biotechnology) was used to lyse 
the cells and the total protein was extracted. The protein concentration was determined by bicinchoninic acid protein assay (Beyotime Institute of Biotechnology). Next, $25 \mu \mathrm{g}$ proteins were loaded onto $15 \%$ SDS-PAGE gels. Following electrophoresis, the proteins were transferred onto nitrocellulose membranes (Shanghai Kang Lang Biological Technology Co., Ltd.). The blots were blocked with $5 \%$ skimmed milk for $1 \mathrm{~h}$ at room temperature. Subsequently, the membrane was incubated with primary rabbit polyclonal antibodies against BAX (1:5,000; cat. no. 50599-2-Ig), Bcl-2 (1:500; cat. no. 26593-1-AP), LC3B (1:300; cat. no. 18725-1-AP), Beclin-1 (1:1,000; cat. no. 3495), Atg5 (1:500; cat. no. 10181-2-AP) (all Wuhan Sanying Biotechnology), cleaved caspase-3 (1:1,000; cat. no. 9664; Cell Signaling Technology, Inc.) and $\beta$-actin (1:10,000; mouse; cat. no. AC004; ABclonal Biotechnology Co., Ltd.) overnight at $4^{\circ} \mathrm{C}$. Subsequently, membranes were washed in TBS with $2 \%$ Tween-20 once and incubated with goat anti-rabbit immunoglobulin G (IgG; 1:2,000; cat. no. AS014; Abclonal Biotechnology Co., Ltd.) or goat anti-mouse $\operatorname{IgG}(1: 2,000$; cat. no. AS003; Abclonal Biotechnology Co., Ltd.) for $1 \mathrm{~h}$ at room temperature. Subsequently, membranes were washed in TBST three times. Digital images of immunoblots were obtained using ProteinSimple FluorChemQ2 and the densitometry of the bands was analyzed using ImageJ software 1.53 (National Institutes of Health).

Statistical analysis. Data analysis was performed by GraphPad Prism 8.0 (GraphPad Software, Inc.). Data are presented as the mean \pm standard deviation of at least three measurements. Data were analyzed using one-way analysis of variance and Tukey's HSD test $(\alpha=0.05)$. $P<0.05$ was considered to indicate a statistically significant difference.

\section{Results}

Ozone increases the viability of H9C2 cells undergoing $O G D / R$. H9C2 cells undergoing OGD/R were treated with different doses of ozone and cell viability was measured by CCK-8 assay. As shown in Fig. 1A, the cell viability was decreased following $\mathrm{OGD} / \mathrm{R}$ treatment. The results also demonstrated that the viability of the cells in ozone groups with concentrations of $10,20,40$ and $60 \mu \mathrm{g} / \mathrm{ml}$ were $61.5 \pm 3.48$, $66.52 \pm 2.33,45.85 \pm 3.93$ and $37.19 \pm 0.19 \%$, respectively. Compared with the OGD/R group, the viability of the cells in the ozone groups with ozone concentrations of 10, 20 and $40 \mu \mathrm{g} / \mathrm{ml}$ were significantly increased $(\mathrm{P}<0.05)$, and the concentration of $20 \mu \mathrm{g} / \mathrm{ml}$ was the most effective (Fig. 1A).

The effect of ozone on the viability of normal H9C2 cells was also analyzed. The results demonstrated that the viability of the cells treated with ozone concentrations of 10, 20, 40 and $60 \mu \mathrm{g} / \mathrm{ml}$ were $94.12 \pm 3.02,94.24 \pm 15.96,93.43 \pm 2.13$ and $101.01 \pm 5.9 \%$, respectively. There was no significant difference among the groups (Fig. 1B).

Ozone inhibits the apoptosis of $H 9 C 2$ cells induced by $O G D / R$. To investigate the effects of different concentrations of ozone on the apoptosis of H9C2 cells, an Annexin V-FITC/PI apoptosis detection kit was used to detect the ratio of apoptosis, and western blotting was performed to detect the apoptosis-related proteins. The results of flow cytometric analysis demonstrated

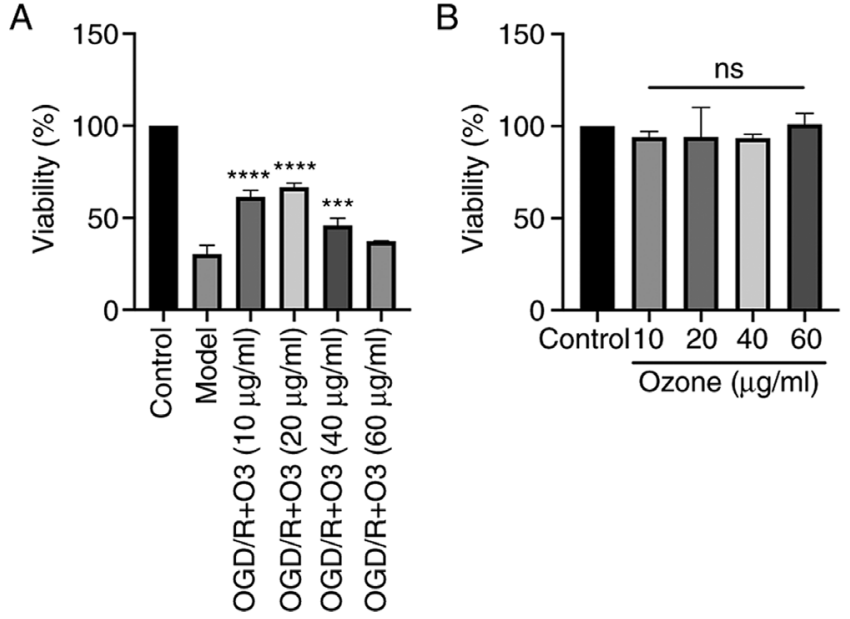

Figure 1. Effect of ozone on viability in OGD/R-treated H9C2 cells. (A) Cell Counting kit- 8 assay demonstrated that the decreased viability of OGD/ R-treated H9C2 cells was attenuated by application of ozone (10, 20, 40 or $60 \mu \mathrm{g} / \mathrm{ml}$ ) during reperfusion. (B) Ozone had no effect on cell viability when H9C2 cells were cultured under normal conditions. Results are presented as the mean \pm standard deviation. ${ }^{* * *} \mathrm{P}<0.001,{ }^{* * * *} \mathrm{P}<0.0001$ versus $\mathrm{OGD} / \mathrm{R}$ group. OGD/R, oxygen-glucose deprivation/reperfusion; ns, not significant.

that the rates of apoptosis in ozone groups with concentrations of $10,20,40$ and $60 \mu \mathrm{g} / \mathrm{ml}$ were $19.03,12.70,19.89$ and $25.45 \%$, respectively. When compared with that of OGD/R group $(40.67 \%)$, the rate of apoptosis in all ozone-treated groups was decreased (Fig. 2). The results of western blotting revealed that the expression of $\mathrm{Bcl}-2$ was increased in response to ozone treatment (10 and $20 \mu \mathrm{g} / \mathrm{ml}$ ) when compared with the control group. Furthermore, the expression of BAX was attenuated in all ozone-treated groups. In addition, the ratio of Bcl-2/BAX was increased and the expression of cleaved caspase-3 was decreased in all groups (Fig. 3A-E).

Ozone inhibits the autophagy of H9C2 cells undergoing $O G D / R$. In order to test the effects of different concentrations of ozone on the autophagy of cardiomyocytes, the expression of autophagy-related proteins was detected by western blotting. The results demonstrated that the expression of autophagy-related proteins (LC3-II/LC3-I, Atg5 and Beclin-1) significantly increased following OGD/R. Compared with the model group, incubation with 20,40 and $60 \mu \mathrm{g} / \mathrm{ml}$ ozone significantly decreased the expression of LC3-II/LC3-I and Beclin-1, and the inhibition effects in the $20 \mu \mathrm{g} / \mathrm{ml}$ group were the most notably. In addition, the expression of Atg5 was decreased following treatment with all concentrations of ozone and $40 \mu \mathrm{g} / \mathrm{ml}$ was the most notably, but there was no statistic difference between the $20 \mu \mathrm{g} / \mathrm{ml}$ and $40 \mu \mathrm{g} / \mathrm{ml}$ ozone groups (Figs. 3F and 4A-C). The aforementioned results indicated that ozone treatment was able to attenuate OGD/R-induced autophagy.

Rapamycin reverses the protective effect of ozone on H9C2 cells undergoing $O G D / R$ and 3-MA further improves the effect. The results demonstrated that the expression of autophagy-related proteins (LC3-II/LC3-I, Atg5 and Beclin-1) was significantly decreased following incubation with the $20 \mu \mathrm{g} / \mathrm{ml}$ ozone and that the autophagy inducer, rapamycin, 

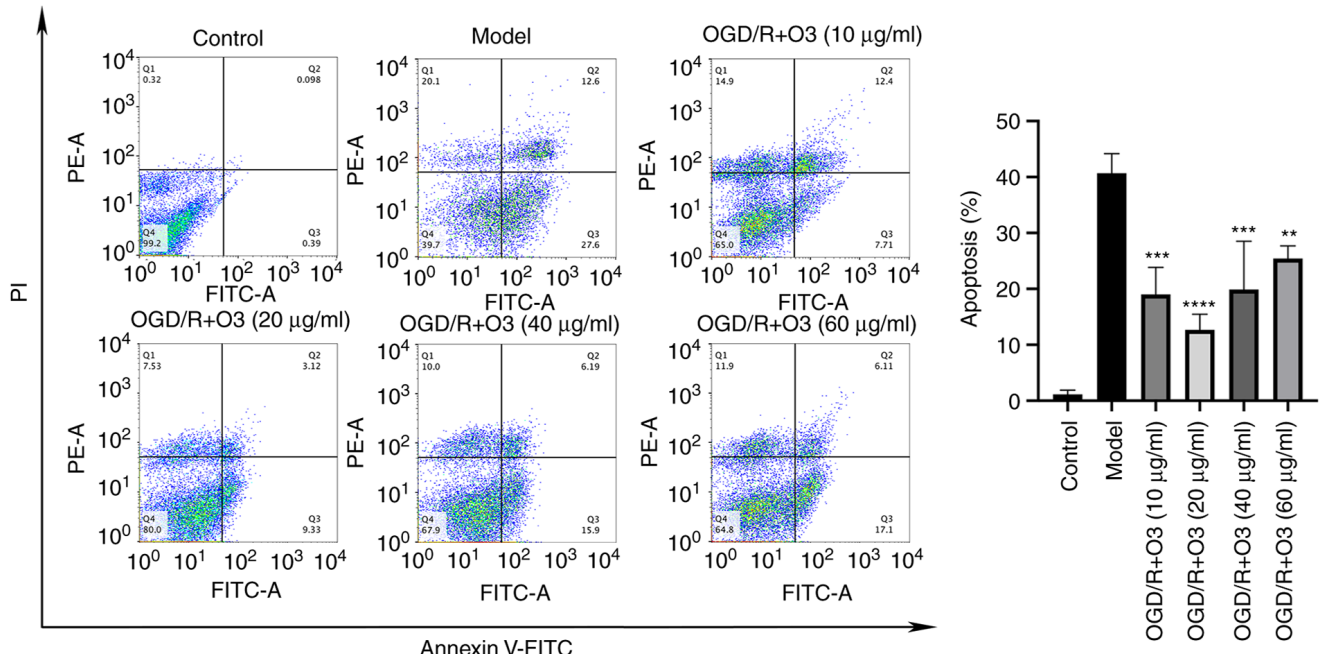

Figure 2. Ozone inhibits apoptosis in OGD/R-treated $\mathrm{H} 9 \mathrm{C} 2$ cells. $\mathrm{H} 9 \mathrm{C} 2$ cells were subjected to oxygen-glucose deprivation injury and then treated with ozone $(10,20,40$ or $60 \mu \mathrm{g} / \mathrm{ml})$ during reperfusion. The rate of apoptosis was assessed using the Annexin V-FITC/PI apoptosis detection kit. Cells in the experiment can be divided into three subgroups: living cells are double negative (Q4); early apoptotic cells are single positive Annexin V-FITC (Q3); late apoptotic cells are double positive for Annexin V-FITC and PI (Q2). The apoptotic rate is the sum of Q2 and Q3. Results are presented as the mean \pm standard deviation of three independent experiments. ${ }^{* *} \mathrm{P}<0.01,{ }^{* * *} \mathrm{P}<0.001,{ }^{* * * * *} \mathrm{P}<0.0001$ versus $\mathrm{OGD} / \mathrm{R}$ group. OGD/R, oxygen-glucose deprivation/reperfusion.
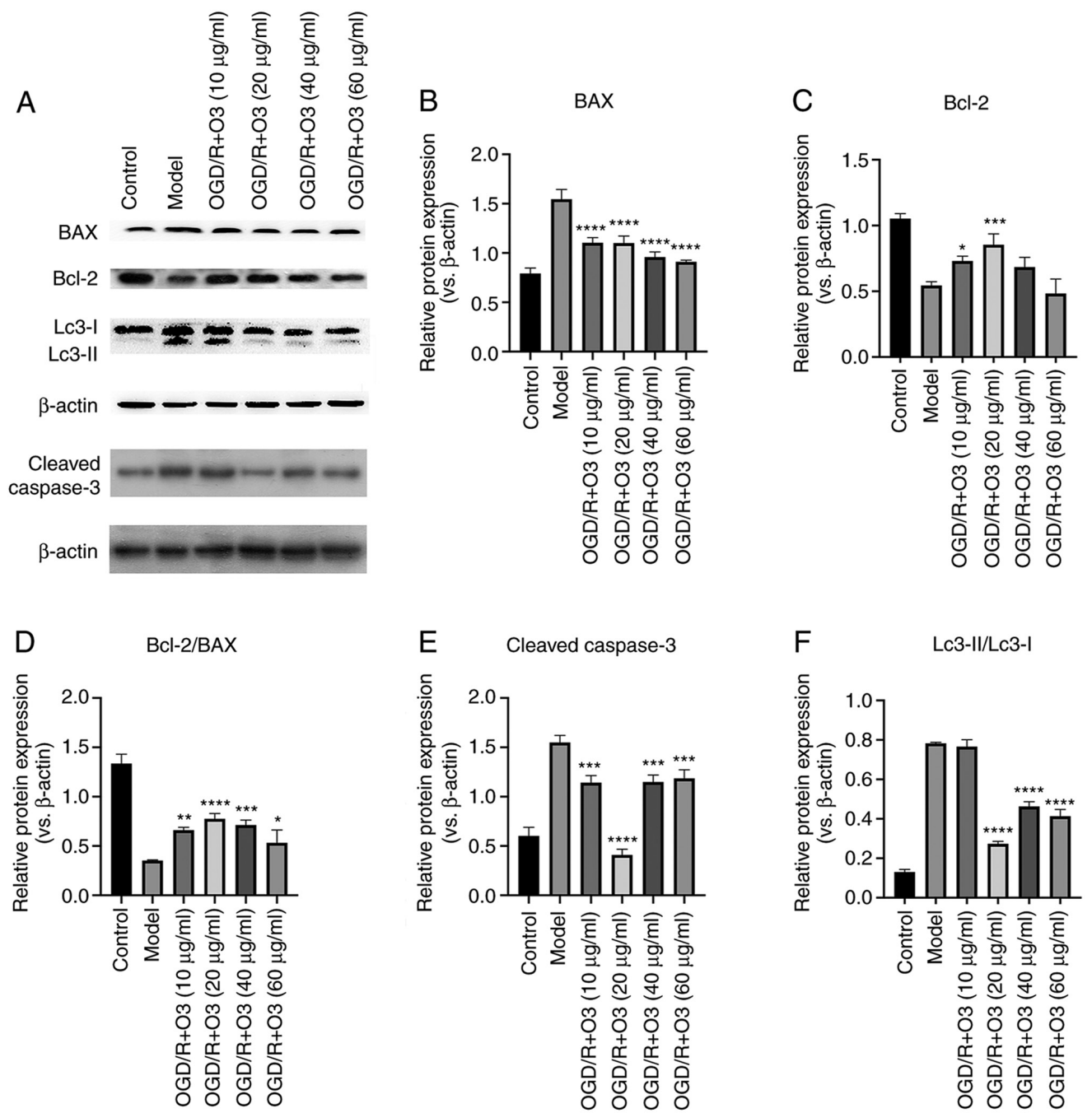

Figure 3. Ozone reduces expression levels of BAX, cleaved caspase-3 and the conversion of LC3 I to LC3 II in H9C2 cells following OGD/R. At the same time, ozone increases expression levels of Bcl-2 and Bcl-2/BAX in cardiomyocyte cells undergoing OGD/R injury. (A) Western blotting was performed and quantified to assess (B) BAX, (C) Bcl-2, (D) Bcl-2/BAX, (E) cleaved caspase-3 and (F) LC3-II/LC3-I protein expression levels. $\beta$-actin was used as the loading control. Results are presented as the mean \pm standard deviation of three independent experiments. ${ }^{*} \mathrm{P}<0.05,{ }^{* *} \mathrm{P}<0.01,{ }^{* * *} \mathrm{P}<0.001,{ }^{* * * * *} \mathrm{P}<0.0001$ versus $\mathrm{OGD} / \mathrm{R}$ group. OGD/R, oxygen-glucose deprivation/reperfusion. 


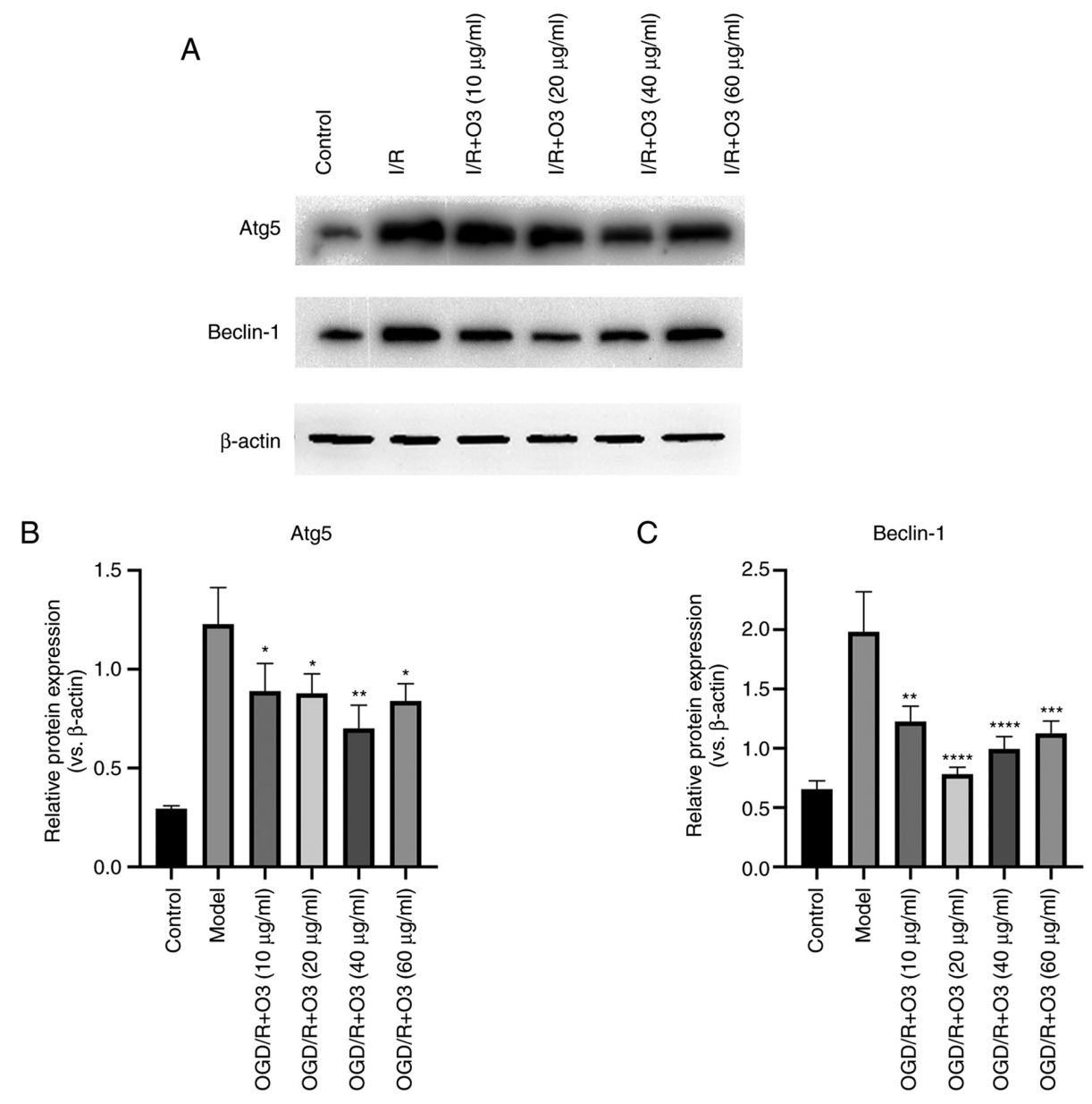

Figure 4. Expression of Atg5 and Beclin-1 were significantly increased following OGD/R and ozone reduces expression levels of those proteins. (A) Western blotting was performed and quantified to assess (B) Atg5 and (C) Beclin-1 protein expression levels. $\beta$-actin was used as the loading control. Results are presented as the mean \pm standard deviation of three independent experiments. ${ }^{*} \mathrm{P}<0.05,{ }^{* *} \mathrm{P}<0.01,{ }^{* * *} \mathrm{P}<0.001,{ }^{* * * *} \mathrm{P}<0.0001$ versus OGD/R group. ATG5, autophagy-related protein 5; OGD/R, oxygen-glucose deprivation/reperfusion.

reversed the effect of ozone. Furthermore, the effect of a decrease in apoptosis-related protein (cleaved casapase-3) expression was also reversed by rapamycin. By contrast, pretreatment with 3-MA notably decreased the expression of Beclin-1 but had no significant effect on the ratio of LC3-II/LC3-I and Atg5 when compared with that of the OGD/R+O3 group (Fig. 5).

Ozone ameliorates the oxidative stress induced by $O G D / R$. In order to elucidate whether ozone affected the oxidative stress in $\mathrm{H} 9 \mathrm{C} 2$ cells, the related indexes of oxidative stress (MDA, LDH and SOD) were detected. The results demonstrated that, compared with the normal cardiomyocytes, the cardiomyocytes that underwent OGD/R had significantly higher contents of MDA and higher LDH activity but lower SOD activity. In groups treated with different concentrations of ozone $(10,20,40$ and $60 \mu \mathrm{g} / \mathrm{ml}$ ozone), the contents of MDA were $0.34 \pm 0.05,0.15 \pm 0.12,0.26 \pm 0.05$ and $0.33 \pm 0.06 \mathrm{nmol} / \mathrm{mg}$ protein, respectively, while that of the $\mathrm{OGD} / \mathrm{R}$ group was $0.5 \pm 0.02 \mathrm{nmol} / \mathrm{mg}$ protein. The activities of LDH were $195.46 \pm 9.35,160.31 \pm 9.2,186.31 \pm 8.3$ and $202.78 \pm 9.68 \mathrm{U} / \mathrm{mg}$ protein, respectively, while that in the OGD/R group was $211.76 \pm 5.3 \mathrm{U} / \mathrm{mg}$ protein. Furthermore, the activities of SOD were $576.83 \pm 3.31,94.09 \pm 7.64,76.74 \pm 6.3$ and
$59.56 \pm 11.98 \mathrm{U} / \mathrm{mg}$ protein, respectively, while the content in model group was $44.28 \pm 3.94 \mathrm{U} / \mathrm{mg}$ protein (Fig. 6).

\section{Discussion}

The results of the present study suggested that OGD/R significantly decreased cell viability and induced apoptosis in cardiomyocytes. Ozone therapy is a novel strategy used in cardio-protection in recent years $(9,20)$. A previous study reported that ozone can significantly ameliorate the ischemia/reperfusion injury following cardio-pulmonary bypass and that ozonated autohemotherapy was beneficial to patients with heart failure with reduced ejection fraction (21). According to the results of the present study, ozone significantly inhibited OGD/R-induced oxidative stress and attenuated cardiomyocyte apoptosis by ameliorating OGD/R-induced activation of autophagy. CCK-8 assay is a highly sensitive method for determining the number of viable cells in cytotoxicity experiments (22) compared with photomicrographs of the cells in which the differences of the cells between ozone treated groups are not clear. According to the results of CCK-8 kit detection in the present study, ozone treatment increased the viability of cardiomyocytes that had undergone OGD/R. Using an isolated rat heart perfusion model, Ahmed et al (9) found 
A
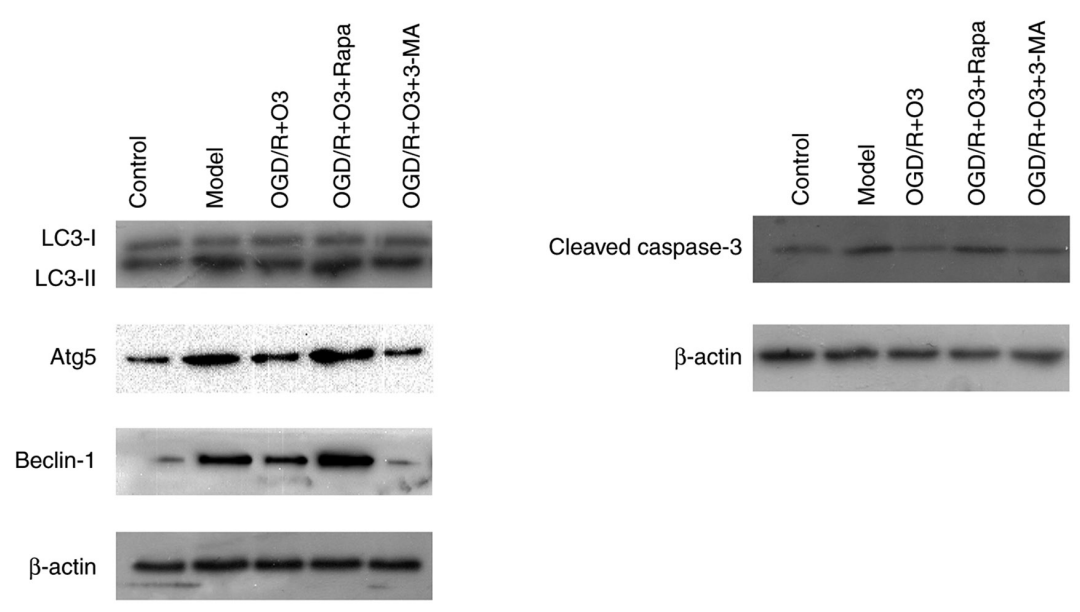

B

LC3-II/LC3-I

C

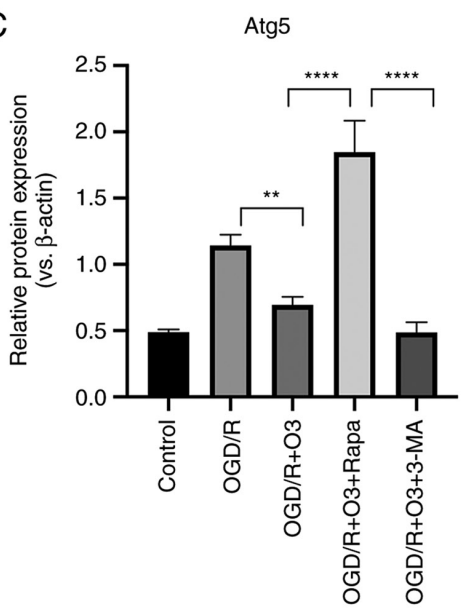

D

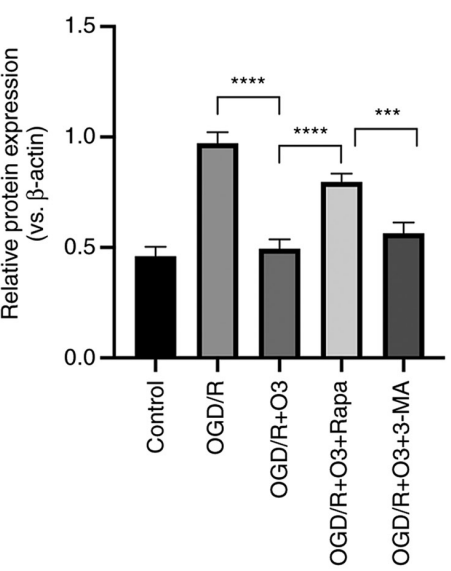

E

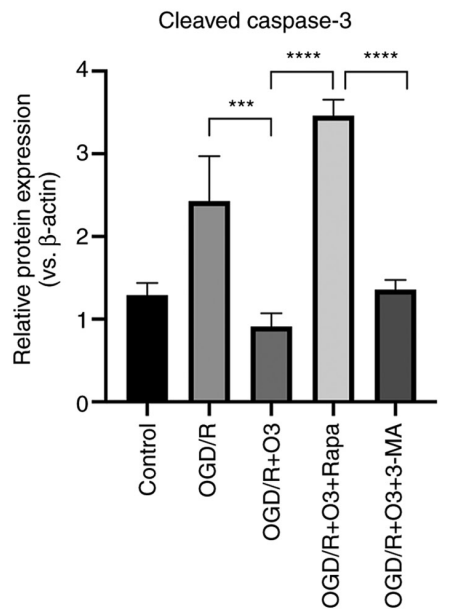

Figure 5. Rapamycin reverses the protective effect of ozone on H9C2 cells undergoing OGD/R and 3-MA further improves this effect. The effect of autophagy inducer, rapamycin and autophagy inhibitor, 3-MA, on H9C2 cells undergoing OGD/R injury. H9C2 cells were pre-treated with rapamycin and 3-MA for $2 \mathrm{~h}$. (A) Western blotting was performed and quantified to determine the protein expression levels of (B) LC3-II/LC3-I, (C) Atg5, (D) Beclin-1 and (E) cleaved caspase-3. $\beta$-actin was used as the loading control. Results are presented as the mean \pm standard deviation of three independent experiments. ${ }^{* *} \mathrm{P}<0.01,{ }^{* * * *} \mathrm{P}<0.001$, ${ }^{* * * * *} \mathrm{P}<0.0001$ versus OGD/R group. ATG5, autophagy-related protein 5; OGD/R, oxygen-glucose deprivation/reperfusion.

that the cardiac function index of rats in the ozone pretreatment group was significantly improved, confirming that ozone had a protective effect on myocardium. However, the protective effect of ozone on cardiomyocytes is associated with its concentration. A previous study demonstrated that the "therapeutic window' of ozone ranging between 10 and $80 \mu \mathrm{g} / \mathrm{ml}$ ensures a small and precise oxidative stress which is able to elicit medical efficacy and no toxicity (23). The present study indicated that the protective effect of ' $20 \mu \mathrm{g} / \mathrm{ml}$ ozone' reached the peak, and then slowly decreased when the concentration of ozone increased, but the protective effect still existed when the concentration was up to $60 \mu \mathrm{g} / \mathrm{ml}$. Notably, the effect of ozone on the viability of cardiomyocytes is associated with the state of the cells. The results of the present study demonstrated that 

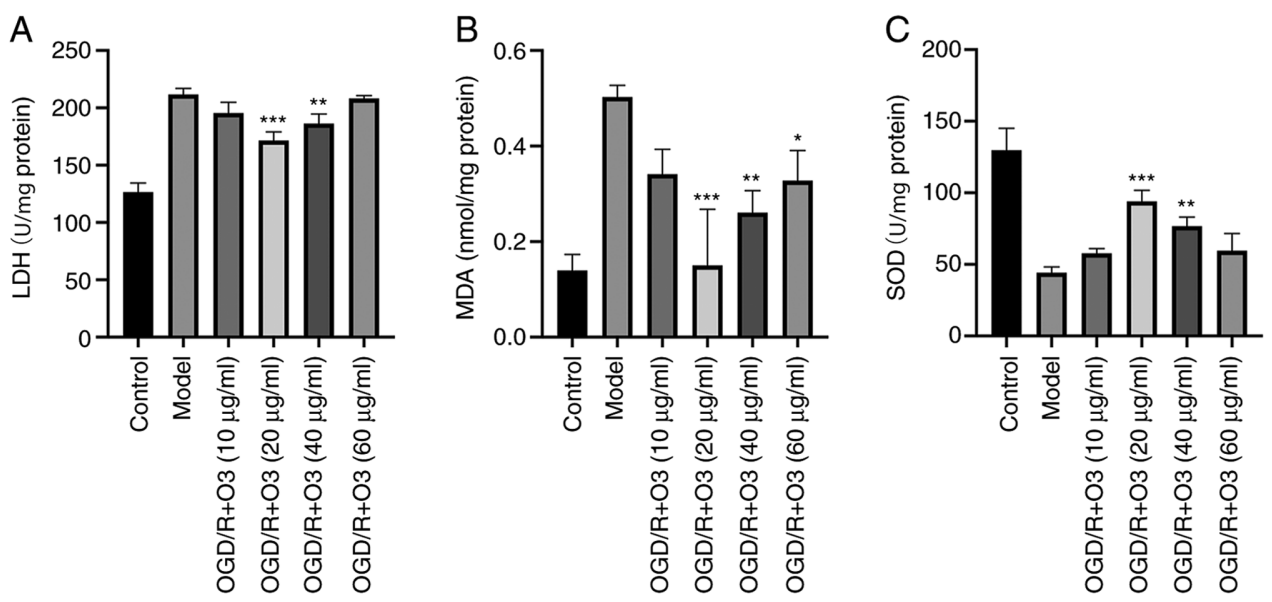

Figure 6. Ozone suppresses LDH and MDA activities but enhances SOD activity in OGD/R-treated H9C2 cells. Cells were treated with ozone (10, 20, 40 or $60 \mu \mathrm{g} / \mathrm{ml}$ ) during reperfusion. (A) LDH activity, (B) content of MDA and (C) SOD activity were detected. ${ }^{*} \mathrm{P}<0.05,{ }^{* *} \mathrm{P}<0.01,{ }^{* * *} \mathrm{P}<0.001 \mathrm{versus} \mathrm{OGD} / \mathrm{R}$ group. LDH, lactate dehydrogenase; MDA, malondialdehyde; SOD, superoxide dismutase; OGD/R, oxygen-glucose deprivation/reperfusion.

the activity of the cells did not change when normal cardiomyocytes were treated with a certain concentration of ozone, which demonstrates that ozone in a certain concentration range would not damage normal cells as it is non-toxic. Therefore, we hypothesized that ozone in a certain concentration range is not toxic to normal cardiomyocytes, but that it could produce a protective effect on myocardial OGD/R injury.

Cell apoptosis is an important consequence of ischemia/reperfusion injury and may be induced by the activation of either extrinsic or intrinsic pathways. A previous study has demonstrated that myocardial OGD/R was associated with apoptosis (6). Among the apoptosis-related proteins, Bcl-2 family and cleaved caspase- 3 are key factors regulating apoptosis (24). Bcl-2 may promote cell survival, but BAX may promote cell death by apoptosis. The ratio of $\mathrm{Bcl}-2 / \mathrm{BAX}$ is the key factor that decides whether apoptosis happens to cells following injuries. In line with the results of a previous study (25), the present study demonstrated that incubation with a low concentration of ozone $(20 \mu \mathrm{g} / \mathrm{ml})$ significantly upregulated the ratio of $\mathrm{Bcl}-2 / \mathrm{BAX}$ and downregulated the expression of cleaved caspase-3 when compared with high concentration $(60 \mu \mathrm{g} / \mathrm{ml})$ ozone and the OGD/R group. Additionally, the results of flow cytometry further demonstrated that incubation with low concentration ozone significantly attenuated the apoptosis rate when compared with the OGD/R group. Based on the aforementioned results, we hypothesized that ozone may decrease the cardiomyocyte apoptosis caused by OGD/R.

Autophagy is a catabolic process aimed to remove damaged proteins or organelles. It is an important mechanism for proteasomal degradation and production of survival signals (26). However, recent studies have reported that the protective function of autophagy is changing $(27,28)$. Additionally, it was demonstrated that autophagy induced cell survival during the process of myocardial ischemic injury, but that it caused cell death during the process of reperfusion injury (28). LC3, Atg5 and Bclin-1 are autophagy-related proteins and several studies have used them to examine autophagy $(23,29)$. The results of the present study suggested that treating $\mathrm{H} 9 \mathrm{C} 2$ cells with ozone at concentrations of $10,20,40$ or $60 \mu \mathrm{g} / \mathrm{ml}$ attenuated the expression of LC3-II/LC3-I, Atg5 and Beclin-1. In addition, treatment with the autophagy inducer, rapamycin, reversed the effect of ozone on decreasing the expression of autophagy-related proteins and apoptosis-related protein. By contrast, the autophagy inhibitor, 3-MA, only decreased the expression of Beclin-1 compared with OGD/R+O3 group, which may be due to the fact that the autophagy during reperfusion is Beclin-1-dependent (30). Therefore, autophagy may be the main target for ozone treatment to prevent myocardial injury induced by OGD/R.

A previous study demonstrated that there is an association between oxidative stress and cell autophagy; therefore, we hypothesized that the internal mechanism of the anti-oxidative stress effect produced by ozone may be associated with autophagy (26). It is easy to induce oxidative stress following OGD/R (31). Oxidative stress is a result of imbalance between the generation of ROS and the antioxidant defense systems (32). LDH and MDA are the important indicators of cellular oxidative stress, and SOD is a protective indicator $(33,34)$. The results of the present study demonstrated that 20,40 and $60 \mu \mathrm{g} / \mathrm{ml}$ ozone decreased LDH and MDA levels and increased SOD release, and that $20 \mu \mathrm{g} / \mathrm{ml}$ ozone was the most effective. The results demonstrated that ozone significantly decreased cellular oxidative stress of cardiomyocytes under OGD/R conditions, suggesting that ozone may exert an anti-autophagy effect on OGD/R-treated cardiomyocytes by blocking oxidative stress.

The present study has certain limitations. It was verified that ozone had no effect on the viability of normal cells and was non-toxic, so groups treated with ozone only have no significance. Moreover, the purpose of the current experiments was to demonstrate that the protective effect of ozone on $\mathrm{H} 9 \mathrm{C} 2$ cells suffering from OGD/R injury was due to autophagy, so groups treated with rapamycin and 3-MA only were not used. Adding these groups will make the experimental design more comprehensive, therefore they will be adopted in future studies. Additionally, the level of oxidative stress of cardiomyocytes when treated with autophagy inhibitors and autophagy inducers needed to be detected to further demonstrate the correlation between autophagy and oxidative stress. Furthermore, the protective molecular pathways were 
not investigated in the present study. All these limitations require further investigation in future studies.

In conclusion, ozone induced tolerance against myocardial OGD/R damage through inhibition of autophagy.

\section{Acknowledgements}

Not applicable.

\section{Funding}

The present study was supported by Jiangsu Provincial Medical Youth Talent (grant no. QNRC2016273) and General Project of Jiangsu Health Committee (grant no. H2018047).

\section{Availability of data and materials}

The datasets used and/or analyzed during the current study are available from the corresponding author on reasonable request.

\section{Authors' contributions}

LX, ZZ and ZW designed the study. LX and LZ performed the experiments. LZ and PL analyzed the data. LX and LZ confirm the authenticity of all the raw data. LX and LZ drafted the manuscript. All authors approved the final version of the manuscript.

\section{Ethics approval and consent to participate}

Not applicable.

\section{Patient consent for publication}

Not applicable.

\section{Competing interests}

The authors declare that they have no competing interests.

\section{References}

1. Granger DN and Kvietys PR: Reperfusion injury and reactive oxygen species: The evolution of a concept. Redox Biol 6: 524-551, 2015.

2. Huang L, Guo B, Liu S, Miao C and Li Y: Inhibition of the LncRNA Gpr19 attenuates ischemia-reperfusion injury after acute myocardial infarction by inhibiting apoptosis and oxidative stress via the miR-324-5p/Mtfr1 axis. IUBMB Life 72: 373-383, 2020.

3. Kuma A, Hatano M, Matsui M, Yamamoto A, Nakaya H, Yoshimori T, Ohsumi Y, Tokuhisa T and Mizushima N: The role of autophagy during the early neonatal starvation period. Nature 432: 1032-1036, 2004.

4. Gurusamy N, Lekli I, Gorbunov NV, Gherghiceanu M, Popescu LM and Das DK: Cardioprotection by adaptation to ischaemia augments autophagy in association with BAG-1 protein. J Cell Mol Med 13: 373-387, 2009.

5. Wu ZQ, Cui SY, Zhu L and Zou ZQ: Study on the Mechanism of mTOR-Mediated Autophagy during Electroacupuncture Pretreatment against Cerebral Ischemic Injury. Evid Based Complement Alternat Med 2016: 9121597, 2016.

6. Gurusamy N, Lekli I, Mukherjee S, Ray D, Ahsan MK, Gherghiceanu M, Popescu LM and Das DK: Cardioprotection by resveratrol: A novel mechanism via autophagy involving the mTORC2 pathway. Cardiovasc Res 86: 103-112, 2010.
7. Matsui Y, Kyoi S, Takagi H, Hsu CP, Hariharan N, Ago T, Vatner SF and Sadoshima J: Molecular mechanisms and physiological significance of autophagy during myocardial ischemia and reperfusion. Autophagy 4: 409-415, 2008.

8. Elvis AM and Ekta JS: Ozone therapy: A clinical review. J Nat Sci Biol Med 2: 66-70, 2011.

9. Ahmed LA, Salem HA, Mawsouf MN, Attia AS and Agha AM: Cardioprotective effects of ozone oxidative preconditioning in an in vivo model of ischemia/reperfusion injury in rats. Scand J Clin Lab Invest 72: 345-354, 2012.

10. Merin O, Attias E, Elstein D, Schwalb H, Bitran D, Zimran A and Silberman S: Ozone administration reduces reperfusion injury in an isolated rat heart model. J Card Surg 22: 339-342, 2007.

11. Di Filippo C, Marfella R, Capodanno P, Ferraraccio F, Coppola L, Luongo M, Mascolo L, Luongo C, Capuano A, Rossi F, et al: Acute oxygen-ozone administration to rats protects the heart from ischemia reperfusion infarct. Inflamm Res 57: 445-449, 2008.

12. Tylicki L, Nieweglowski T, Biedunkiewicz B, Chamienia A, Debska-Slizien A, Aleksandrowicz E, Lysiak-Szydlowska W and Rutkowski B: The influence of ozonated autohemotherapy on oxidative stress in hemodialyzed patients with atherosclerotic ischemia of lower limbs. Int J Artif Organs 26: 297-303, 2003.

13. Foglieni C, Fulgenzi A, Belloni D, Sciorati C, Ferrero E and Ferrero ME: Ozonated autohemotherapy: Protection of kidneys from ischemia in rats subjected to unilateral nephrectomy. BMC Nephrol 12: 61, 2011.

14. Filomeni G, Desideri E, Cardaci S, Rotilio G and Ciriolo MR: Under the ROS...thiol network is the principal suspect for autophagy commitment. Autophagy 6: 999-1005, 2010.

15. Al-Salam S and Hashmi S: Myocardial Ischemia Reperfusion Injury: Apoptotic, Inflammatory and Oxidative Stress Role of Galectin-3. Cell Physiol Biochem 50: 1123-1139, 2018.

16. Chen Y, Azad MB and Gibson SB: Superoxide is the major reactive oxygen species regulating autophagy. Cell Death Differ 16: 1040-1052, 2009.

17. Gustafsson AB and Gottlieb RA: Eat your heart out: Role of autophagy in myocardial ischemia/reperfusion. Autophagy 4: 416-421, 2008

18. Kroemer G, Mariño G and Levine B: Autophagy and the integrated stress response. Mol Cell 40: 280-293, 2010.

19. Chen J, Jiang Z, Zhou X, Sun X, Cao J, Liu Y and Wang X: Dexmedetomidine Preconditioning Protects Cardiomyocytes Against Hypoxia/Reoxygenation-Induced Necroptosis by Inhibiting HMGB1-Mediated Inflammation. Cardiovasc Drugs Ther 33: 45-54, 2019.

20. El-Sawalhi MM, Darwish HA, Mausouf MN and Shaheen AA: Modulation of age-related changes in oxidative stress markers and energy status in the rat heart and hippocampus: A significant role for ozone therapy. Cell Biochem Funct 31: 518-525, 2013

21. Buyuklu M, Kandemir FM, Set T, Bakırc1 EM, Degirmenci H, Hamur H, Topal E, Kucukler S and Turkmen K: Beneficial Effects of Ozone Therapy on Oxidative Stress, Cardiac Functions and Clinical Findings in Patients with Heart Failure Reduced Ejection Fraction. Cardiovasc Toxicol 17: 426-433, 2017.

22. Li Y, Xia J, Jiang N, Xian Y, Ju H, Wei Y and Zhang X: Corin protects $\mathrm{H}_{2} \mathrm{O}_{2}$-induced apoptosis through $\mathrm{PI} 3 \mathrm{~K} / \mathrm{AKT}$ and NF- $\kappa \mathrm{B}$ pathway in cardiomyocytes. Biomed Pharmacother 97: 594-599, 2018.

23. Sagai M and Bocci V: Mechanisms of Action Involved in Ozone Therapy: Is healing induced via a mild oxidative stress? Med Gas Res 1: 29, 2011.

24. Zhu L, Hao J, Cheng M, Zhang C, Huo C, Liu Y, Du W and Zhang X: Hyperglycemia-induced Bcl-2/Bax-mediated apoptosis of Schwann cells via mTORC1/S6K1 inhibition in diabetic peripheral neuropathy. Exp Cell Res 367: 186-195, 2018.

25. Cai HA, Tao X, Zheng LJ, Huang L, Peng Y, Liao RY and Zhu YM: Ozone alleviates ischemia-reperfusion injury by inhibiting mitochondrion-mediated apoptosis pathway in SH-SY5Y cells. Cell Biol Int 44: 975-984, 2020.

26. Filomeni G, De Zio D and Cecconi F: Oxidative stress and autophagy: The clash between damage and metabolic needs. Cell Death Differ 22: 377-388, 2015.

27. Du J, Li Y and Zhao W: Autophagy and myocardial ischemia. In: Autophagy: Biology and Diseases. Le W (ed). Springer, Singapore. Adv Exp Med Biol 1207: 217-222, 2020.

28. Shi B, Ma M, Zheng Y, Pan Y and Lin X: mTOR and Beclin1: Two key autophagy-related molecules and their roles in myocardial ischemia/reperfusion injury. J Cell Physiol 234: 12562-12568, 2019. 
29. Galluzzi L and Green DR: Autophagy-Independent Functions of the Autophagy Machinery. Cell 177: 1682-1699, 2019.

30. Pattingre S, Tassa A, Qu X, Garuti R, Liang XH, Mizushima N, Packer M, Schneider MD and Levine B: Bcl-2 antiapoptotic proteins inhibit Beclin 1-dependent autophagy. Cell 122: 927-939, 2005

31. Kurian GA, Rajagopal R, Vedantham S and Rajesh M: The Role of Oxidative Stress in Myocardial Ischemia and Reperfusion Injury and Remodeling: Revisited. Oxid Med Cell Longev 2016: $1656450,2016$.

32. Sinha N and Dabla PK: Oxidative stress and antioxidants in hypertension-a current review. Curr Hypertens Rev 11: 132-142, 2015.
33. Yang F, Pei R, Zhang Z, Liao J, Yu W, Qiao N, Han Q, Li Y, $\mathrm{Hu} \mathrm{L}$, Guo J, et al: Copper induces oxidative stress and apoptosis through mitochondria-mediated pathway in chicken hepatocytes. Toxicol In Vitro 54: 310-316, 2019

34. Huang Z, Ji H, Shi J, Zhu X and Zhi Z: Engeletin Attenuates A $\beta 1-42-$ Induced Oxidative Stress and Neuroinflammation by Keap1/Nrf2 Pathway. Inflammation 43: 1759-1771, 2020.

This work is licensed under a Creative Commons Attribution-NonCommercial-NoDerivatives 4.0 International (CC BY-NC-ND 4.0) License. 